\title{
PLASMA NEUROPEPTIDE Y AND CATECHOLAMINES IN PEDIATRIC PATIENTS UNDERGOING CARDIAC OPERATIONS
}

Lena S. Sun, $\mathrm{MD}^{\mathrm{a}, \mathrm{b}}$

Fang Du, MPH ${ }^{a}$

William S. Schechter, $\mathrm{MD}^{\mathrm{a}, \mathrm{b}}$

Jan M. Quaegebeur MD, $\mathrm{PhD}^{c}$

Yvonne Vulliemoz, $\mathrm{PhD}^{\mathrm{a}, \mathrm{d}}$

\begin{abstract}
Objective: Our objective was to assess the sympathoadrenal response in pediatric patients undergoing repair of congenital cardiac defects. Methods: Plasma catecholamine (norepinephrine and epinephrine) and neuropeptide $Y$ concentrations were quantified before and after cardiopulmonary bypass to assess the response to cardiopulmonary bypass. To determine the response to aortic occlusion, levels of plasma catecholamines and neuropeptide $Y$ were measured at the time of and immediately after release of the aortic crossclamp. Results: During cardiopulmonary bypass, no significant change in levels of plasma norepinephrine $(n=43)$, epinephrine $(n=$ $37)$, or neuropeptide $Y(n=46)$ was observed. Aortic occlusion induced a significant increase in plasma neuropeptide $Y$, but not in catecholamines. There was a greater increase in plasma neuropeptide $\mathrm{Y}$ in children older than age 1 year than in those younger than 1 year. Conclusions: Plasma neuropeptide $Y$ may be a useful marker of sympathetic nervous system activity. Children younger than age 1 year showed a lesser sympathetic response compared with the response in older children. (J Thorac Cardiovasc Surg 1997;113:278-84)
\end{abstract}

T he response of the sympathetic nervous system to operation and cardiopulmonary bypass (CPB) has been extensively studied in adults. ${ }^{1,2}$ Anand and Hickey ${ }^{3}$ and Anand, Hansen, and Hickey ${ }^{4}$ have also examined this response in neonates undergoing cardiac operations for repair of congenital cardiac defects. In all studies to date the "sympathoadrenal stress response" has been assessed by changes in plasma catecholamine levels. Plasma catecholamines, particularly plasma norepinephrine, used as a "window" to examine the activation of the sympathetic nervous system may not be a sufficiently sensitive marker because plasma norepinephrine represents only a fraction of the actual amount released from sympathetic nerve terminals, most of which is either recaptured or metabolized. ${ }^{5}$ The

From the Departments of Anesthesiology, ${ }^{a}$ Pediatrics, ${ }^{b}$ Surgery, ${ }^{c}$ and Pharmacology, ${ }^{\mathrm{d}}$ College of Physicians and Surgeons, Columbia University, New York, N.Y.

Supported in part by a Young Investigator Award from the Foundation for Anesthesia Education and Research.

Received for publication March 20, 1996; revisions requested May 20, 1996; revisions received August 19, 1996; accepted for publication August 20, 1996.

Address for reprints: Lena S. Sun, MD, BH4-440N, 622 W. 168th St., New York, NY 10032.

Copyright (C) 1997 by Mosby-Year Book, Inc.

$0022-5223 / 97 \$ 5.00+0 \quad \mathbf{1 2 / 1} / 77397$ sensitivity and accuracy of plasma norepinephrine used as a measure of the activity of the immature sympathetic nervous system are even less certain. The highest plasma norepinephrine concentrations, unrelated to catecholamine-secreting tumors, have been reported in the human neonate. In neonates undergoing cardiac operation, very high concentrations of plasma norepinephrine and epinephrine have been documented preoperatively. ${ }^{3,4}$ Because the cardiovascular sympathetic neuroeffector system continues to mature in the postnatal period, agerelated changes in the sympathoadrenal stress response might also occur. ${ }^{6}$ Thus, in neonates, the high circulating catecholamine levels might be a result of incomplete development of the reuptake mechanism for norepinephrine or immaturity of enzyme systems that metabolize catecholamines, or both these reasons, or a result of an enhanced activation of the sympathetic nervous system.

Plasma neuropeptide Y (NPY), a 36 amino acid peptide, has often been used as noncatecholamine marker for sympathetic neural activity. NPY was first isolated in 1982 and is abundant in the cardiovascular system, where it colocalizes with norepinephrine in the sympathetic nerve endings. ${ }^{7}$ During intense sympathetic neural stimulation, NPY is coreleased with norepinephrine and functions both directly as a neuromediator and indirectly as a 
neuromodulator. ${ }^{8}$ Both plasma catecholamine and NPY concentrations are elevated with activation of the sympathetic nervous system in human subjects. ${ }^{9,}{ }^{10}$ In adult patients undergoing cardiac operation, aortic occlusion elicits increases both in catecholamines and NPY as part of the metabolichormonal stress response. ${ }^{2}$ There is no reuptake of NPY released from nerve endings. It is metabolized solely by plasma peptidases. Its plasma half-life is between 20 and 30 minutes, which is much longer than that of plasma catecholamines with a half-life of about 2 minutes. ${ }^{11}$

We examined the effect of CPB and aortic occlusion on plasma catecholamines and NPY in children of various ages to determine whether there are age-related changes in the sympathoadrenal stress response. Furthermore, we compared the changes in plasma catecholamine concentrations with those of plasma NPY to determine whether plasma NPY may be a useful marker of sympathetic nervous system activity in the pediatric patient.

\section{Methods}

After approval from the Institutional Review Board for human studies, we obtained written, informed consent from parents of patients enrolled in the study. All subjects were undergoing elective cardiac operation at the Babies and Children's Hospital done by a single pediatric cardiothoracic surgeon (J. M. Q.) during the period from December 1991 to June 1994. All patients underwent nonpulsatile hypothermic CPB.

Anesthesia was induced with fentanyl, $25 \mu \mathrm{g} / \mathrm{kg}$, and the lungs were ventilated with $100 \% \mathrm{O}_{2}$. Vecuronium was used for muscle relaxation. A total dose of fentanyl of 100 $\mu \mathrm{g} / \mathrm{kg}$ was administered to all patients before initiation of CPB. Fentanyl was administered by intravenous bolus injections between the time of sternotomy and initiation of CPB. At the discretion of the attending anesthesiologist, isoflurane or halothane was used to supplement anesthesia, as needed, before CPB. Nitroprusside infusion at a dose of 1 to $4 \mu \mathrm{g} / \mathrm{kg}$ was administered to facilitate cooling and rewarming to the predetermined core temperature as requested by the surgeon. Additional vecuronium and a dose of $0.15 \mathrm{mg} / \mathrm{kg}$ of midazolam were given at rewarming. The total dose of fentanyl (on a per kilogram of body weight basis) was the same for all patients at each of the sampling points indicated later in this section. The choice and doses of inotropic agents administered on separation from $\mathrm{CPB}$ and during the postoperative period were at the discretion of the attending anesthesiologist. Patients were excluded from the study if they were receiving an inotropic agent before the operation.

Four samples of blood were obtained from all patients as follows: (1) after induction of anesthesia with a 25 $\mu \mathrm{g} / \mathrm{kg}$ dose of fentanyl, when hemodynamic parameters were stable for at least 10 minutes, and before surgical incision (pre-CPB); (2) during hypothermic bypass and
Table I. Patient characteristics and intraoperative events

\begin{tabular}{ll}
\hline Age (mo) & Median 11.5 (range 1 day-211 mo) \\
Weight $(\mathrm{kg})$ & $10.7 \pm 8.8$ (range 2.4-40) \\
Gender & 30 male/16 female \\
Total CPB time (min) & $102.8 \pm 47.5(95 \%$ CI $88.7-116.9)$ \\
$\begin{array}{l}\text { Aortic crossclamp time } \\
\quad(m i n)\end{array}$ & $54.0 \pm 27.0(95 \%$ CI $46.0-62.0)$ \\
Lowest temperature & $24.8 \pm 0.7$ (range 18-32) \\
$\quad$ during CPB $\left({ }^{\circ} \mathrm{C}\right)$ & \\
\hline
\end{tabular}

Data are expressed as means plus or minus standard deviation, unless otherwise specified.

within 1 minute after the application of the aortic crossclamp (pre-AO); (3) during bypass and rewarming, within 1 minute after removal of the aortic crossclamp (post$\mathrm{AO}$ ); and (4) at the conclusion of CPB, when the patient was normothermic (post-CPB).

Blood samples were collected from an indwelling arterial catheter (time points 1 and 4) or directly from the CPB machine (time points 2 and 3 ) into prechilled tubes containing aprotinin and ethylenediaminetetraacetic acid. They were centrifuged at $4^{\circ} \mathrm{C}$ and the separated plasma was stored at $-70^{\circ} \mathrm{C}$ until assayed for NPY and catecholamines. Plasma NPY was measured with use of a radioimmunoassay kit (Peninsula Laboratories). The sensitivity of the radioimmunoassay was $2 \mathrm{pg} / \mathrm{ml}$. Plasma epinephrine and norepinephrine concentrations were determined by high-performance liquid chromatography. The sensitivity of the assay was $50 \mathrm{pg} / \mathrm{ml}$. The interassay variability was $5 \%$, with a range from $1.5 \%$ to $6.5 \%$. Average recovery was $80.8 \% \pm 7 \%$ (mean plus or minus standard deviation) for norepinephrine and $83.9 \% \pm 3 \%$ (mean plus or minus standard deviation) for epinephrine.

Data analysis. A total of 43 samples were available for plasma norepinephrine analysis and 37 for epinephrine analysis. Analysis of variance by repeated measures was done to assess intraoperative changes in plasma NPY and catecholamine levels. Differences between pre-CPB and post-CPB levels were analyzed by post hoc testing with Scheffe's test between points 1 and 4 . Changes during aortic occlusion were assessed by Scheffe's test between points 2 and 3. Regression analysis and curve fitting between prebypass plasma NPY or catecholamine concentrations as a function of age were done to determine whether there were age-dependent changes. ${ }^{12}$ Plasma NPY and catecholamine level differences between the two age groups were analyzed by unpaired $t$ test for single time points and by factorial analysis of variance for multiple time points. ${ }^{12}$ Unpaired $t$ test was used to compare plasma NPY concentrations in patients with and without cyanotic lesions. To examine the interaction between age, pre-CPB NPY levels, pre-AO NPY levels, and the relative change in NPY concentration during aortic occlusion, we performed multiple regression analysis and analysis of covariance using changes in plasma NPY concentration during aortic occlusion as the dependent variable and age, pre-CPB NPY level, and pre-AO NPY level as independent variables. ${ }^{12}$ Multiple regression analysis was also used to examine the interaction between age and temperature with changes in NPY concen- 


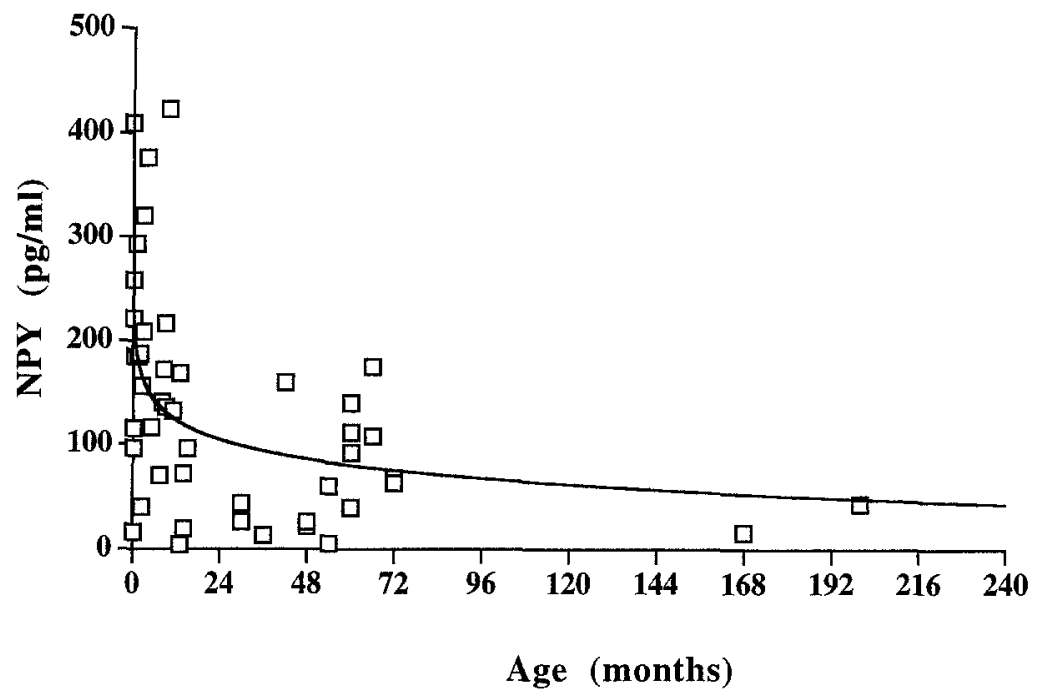

Fig. 1. Age-dependent changes in level of plasma NPY pre-CPB $(r=+0.505,95 \% \mathrm{CI}+0.31,+0.89, p=$ $0.0028, n=46)$.

Table II. Patient characteristics for the two age groups

\begin{tabular}{lll}
\hline & \multicolumn{1}{c}{$<1$ yr $(n=23)$} & \multicolumn{1}{c}{$>1$ yr $(n=23)$} \\
\hline Age (mo) & $3.8 \pm 3.7$ (range 1 day-11 mo) & $60 \pm 53.4(\text { range } 12-211 \mathrm{mo})^{*}$ \\
Weight $(\mathrm{kg})$ & $4.9 \pm 2.5$ (range 2.4-12.2) & $16.6 \pm 9.0($ range 5.2-40)* \\
Gender & 15 male/8 female & 15 male/8 female \\
Preoperative medications & Digoxin and furosemide/diuretics (8); prostaglandin $E_{1}(6)$ & Digoxin and furosemide/diuretics (8) \\
Diagnosis & Ventricular septal defect (3) & Ventricular septal defect (4) \\
& Atrioventricular canal (4) & Atrioventricular canal (3) \\
& Tetralogy of Fallot (3) & Tetralogy of Fallot (6) \\
& Hypoplastic left heart syndrome (1) & Atrial septal defect (2) \\
& Transposition of great vessels (4) & Transposition of great vessels (2) \\
& Truncus arteriosus (3) & Mitral valve disease (1) \\
& Total/partial anomalous pulmonary venous return (2) & Aortic valve disease (4) \\
& Single ventricle (2) & Single ventricle (1) \\
& Pulmonary-aortic window (1) &
\end{tabular}

Numbers in parentheses refer to number of patients. Data are expressed as means plus or minus standard deviation, unless otherwise specified. ${ }^{*} p<0.05$ compared with $<1$-year-old patients.

Table III. Intraoperative events for the two age groups

\begin{tabular}{lll}
\hline & \multicolumn{1}{c}{$<1$ yr $(n=23)$} & \multicolumn{1}{c}{$>1$ yr $(n=23)$} \\
\hline Total CPB time (min) & $104.6 \pm 37.3(95 \%$ CI $88.4-120.7)$ & $101.1 \pm 56.8(95 \%$ CI $76.5-125.6)$ \\
Aortic crossclamp time (min) & $53.8 \pm 23.1(95 \%$ CI 43.9-63.8) & $54.2 \pm 31.0(95 \%$ CI 40.8-67.6) \\
Lowest temperature during CPB $\left({ }^{\circ} \mathrm{C}\right)$ & $22.96 \pm 5.4$ (range 18-32) & $26.6 \pm 3.3($ range 24-32) \\
No. of patients receiving inhaled agents & 4 & 9
\end{tabular}

Data are expressed as means plus or minus standard deviation, unless otherwise specified.

${ }^{*} p<0.05$ compared with $<1$-year-old patients.

tration during aortic occlusion. All appropriate data are expressed as means plus or minus the standard error of the mean. A value of $p<0.05$ was deemed significant.

\section{Results}

Patient characteristics and intraoperative events. Patient characteristics and intraoperative course are summarized in Table I.
Patient age and plasma catecholamine and NPY concentrations. Pre-CPB plasma NPY level was significantly correlated with age $(r=+0.505,95 \%$ confidence interval $[\mathrm{CI}]+0.31,+0.89, p=0.0028$ ). With increasing age, there was a gradual decline in level of plasma NPY, with the sharpest decline taking place during the first year (Fig. 1). No such 
correlation was found with either plasma epinephrine or norepinephrine (data not shown).

Plasma catecholamine and NPY levels during CPB and aortic occlusion. Plasma catecholamine levels were extremely variable among the pediatric patients undergoing cardiac operations. There was no significant change in plasma norepinephrine, epinephrine (Fig. 2, A), or NPY (Fig. 2, B) concentrations after CPB compared with before CPB. In response to aortic occlusion, plasma catecholamine concentrations remained unchanged, but there was a significant increase in plasma NPY (Fig. 2, $A$ and $B$ ).

Catecholarnine and NPY levels in two different age groups. Because the decline in pre-CPB plasma NPY concentrations was greatest in patients operated on during their first year of life, patients were divided into two groups: those younger and those older than age 1 year. Summaries of patient characteristics and intraoperative events for the two age groups are presented in Tables II and III. There were no significant differences between the two groups except for age and the lowest temperature attained during CPB. The total dose of fentanyl was the same at each sampling point, on a per kilogram of weight basis. Only a minor proportion of each group received supplemental inhaled agents.

In each age group, changes in plasma catecholamine (Fig. 3, $A$ ) and NPY (Fig. 3, B) concentrations during $\mathrm{CPB}$ and aortic occlusion were expressed as percent change from pre-CPB and pre-AO values, respectively. Though children older than age 1 year appeared to have larger increases in norepinephrine and epinephrine levels during $\mathrm{CPB}$ and aortic occlusion (Fig. 3, $A$ ), there was no statistically significant increase in either age group because of the large interpatient variability. Similarly, there was no significant increase in plasma NPY concentration during CPB in either age group. In contrast, plasma NPY levels increased significantly during aortic occlusion $(p=0.0005)$, and values in the older age group increased significantly more $(p=0.0003)$ than those in the younger group $(p=0.035)$ (Fig. 3, B). Multiple regression analysis revealed that the age-dependent plasma NPY response could not be accounted for by the fact that the younger children had much higher pre-CPB $(r=$ $+0.001, p=0.667)$ and pre-AO $(r=-0.002, p=$ $0.201)$ plasma NPY concentrations.

Effect of cyainosis and temperature on changes in plasma NPY levels during aortic occlusion. We further examined whether the presence of cyanotic
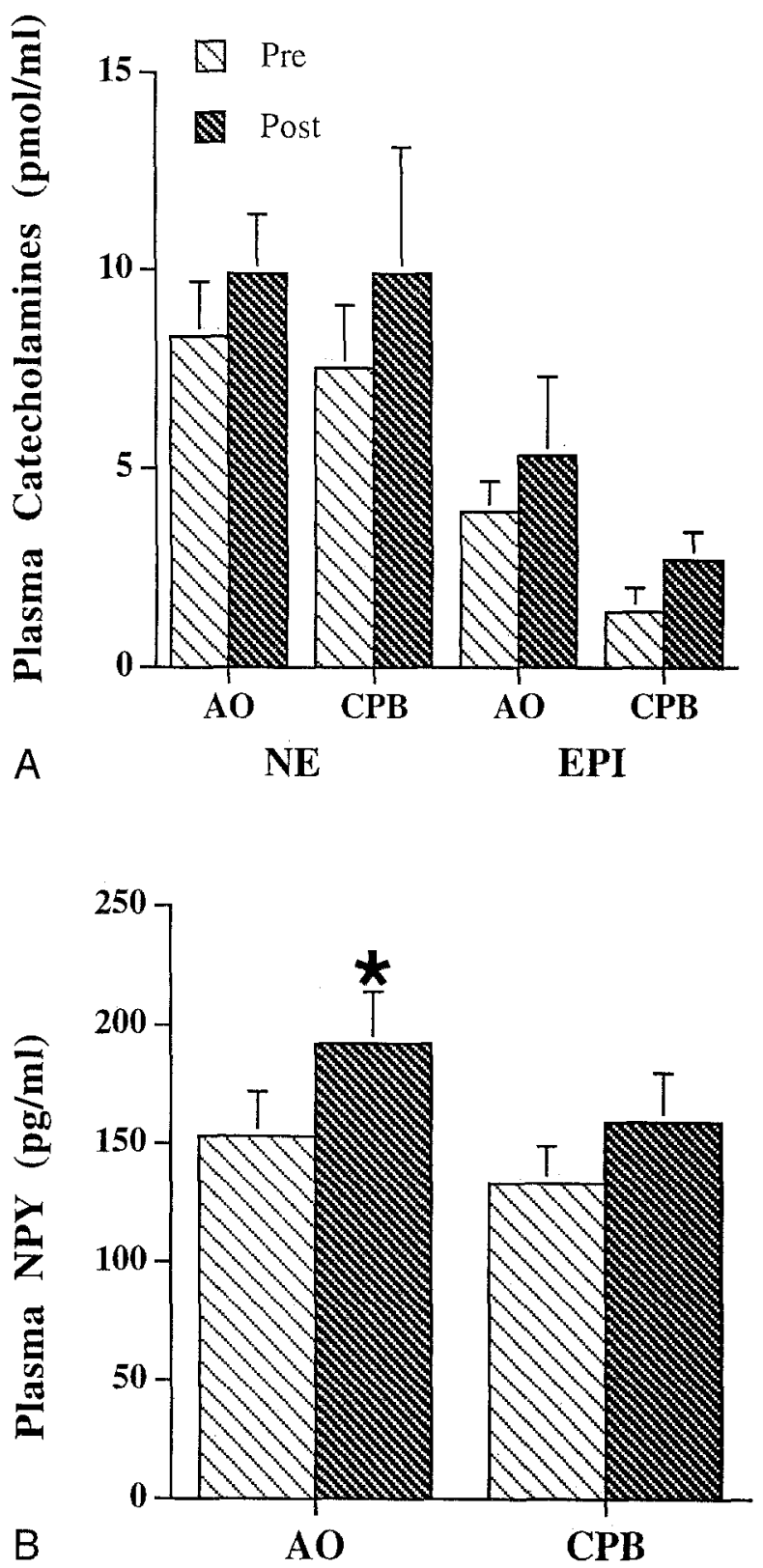

Fig. 2. Data are expressed as means plus or minus the standard error of the mean. A, Changes in plasma concentrations of norepinephrine $(N E)(n=43)$ and epinephrine (EPI) $(n=37)$ during $\mathrm{CPB}$ and aortic occlusion $(A O)$ : pre-CPB, norepinephrine $7.5 \pm 1.6$ $\mathrm{pmol} / \mathrm{ml}$; pre-CPB, epinephrine $1.4 \pm 0.6 \mathrm{pmol} / \mathrm{ml}$ pre-AO, norepinephrine $8.2 \pm 1.4 \mathrm{pmol} / \mathrm{ml}$; pre-AO, epinephrine $4.8 \pm 1.2 \mathrm{pmol} / \mathrm{ml}$. B, Changes in plasma NPY concentrations during CPB and aortic occlusion. Plasma NPY level did not change from pre-CPB to post-CPB measurement, but increased significantly from pre-AO to post-AO measurement: pre-CPB, NPY $136.3 \pm 16.1 \mathrm{pg} / \mathrm{ml}$; pre-AO, NPY $153.3 \pm 19.3 \mathrm{pg} / \mathrm{ml}$. ${ }^{*} p<0.05$ post-AO versus pre-AO. 

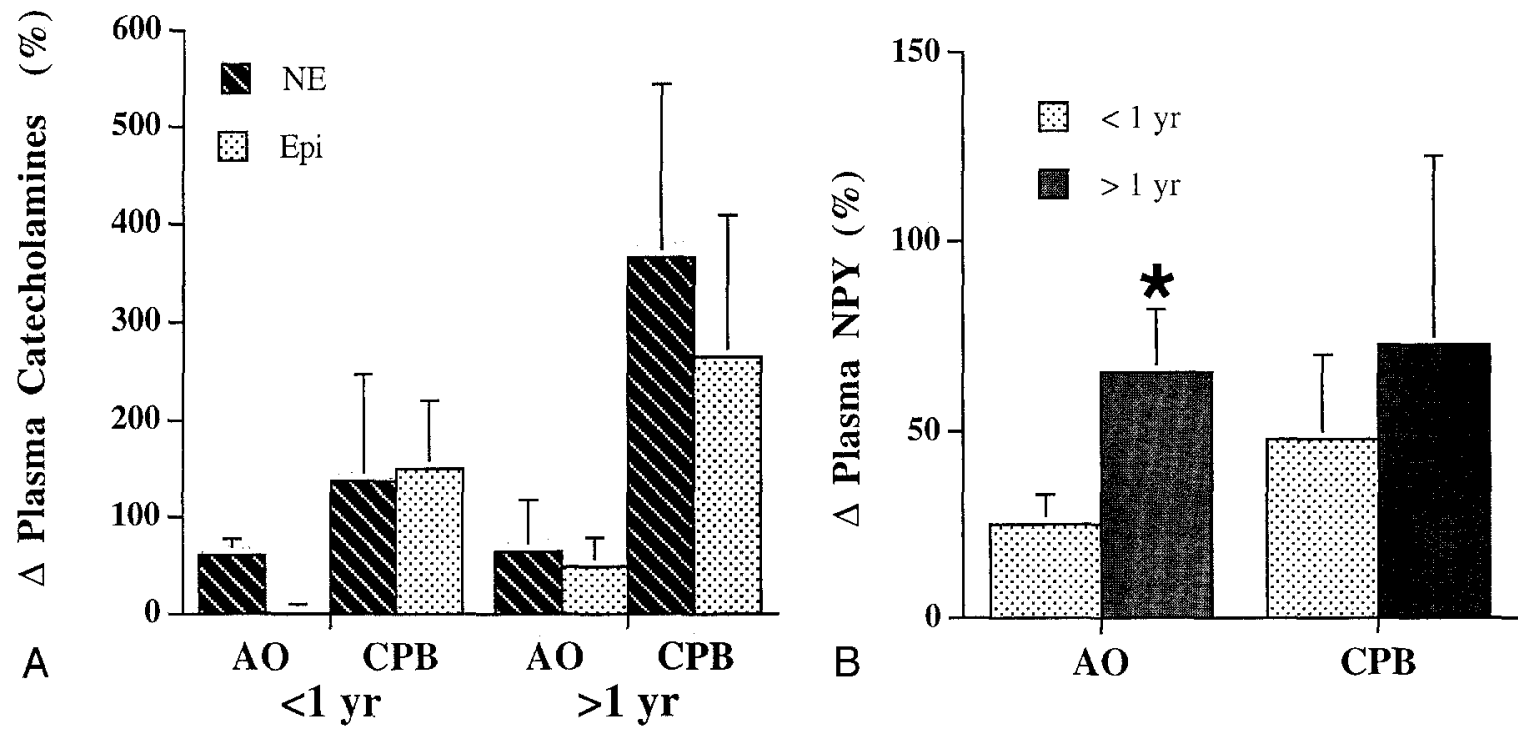

Fig. 3. Data are expressed as means plus or minus the standard error of the mean. Relative changes in levels of plasma catecholamines and NPY during CPB and aortic occlustion $(A O)$ for children older $(n=$ $23)$ and younger $(n=23)$ than age 1 year are depicted. Data are expressed as percent change $(\Delta)$ from values before CPB or before aortic occlusion. A, Changes in levels of plasma norepinephrine (NE) and epinephrine (Epi) in the two groups during $\mathrm{CPB}$ and aortic occlusion did not differ significantly: younger than 1 year, pre-AO norepinephrine $8.8 \pm 1.9 \mathrm{pmol} / \mathrm{ml}(n=22)$; pre-AO epinephrine $1.9 \pm 0.7 \mathrm{pmol} / \mathrm{ml}$ $(n=19)$; pre-CPB norepinephrine $8.5 \pm 2.0 \mathrm{pmol} / \mathrm{ml}(n=22)$; pre-CPB epinephrine $0.9 \pm 0.3 \mathrm{pmol} / \mathrm{ml}$ $(n=19)$ and older than 1 year, pre-AO norepinephrine $7.5 \pm 2.2 \mathrm{pmol} / \mathrm{ml}(n=21)$; pre-AO epinephrine $7.7 \pm 2.0 \mathrm{pmol} / \mathrm{ml}(n=18) ; \mathrm{pre}-\mathrm{CPB}$ norepinephrine $6.4 \pm 2.5 \mathrm{pmol} / \mathrm{ml}(n=21) ; \mathrm{pre}-\mathrm{CPB}$ epinephrine $1.9 \pm 0.3 \mathrm{pmol} / \mathrm{ml}(n=18)$. B, Changes in plasma NPY concentration in children older $(n=23)$ and younger $(n=23)$ than age 1 year during CPB and aortic occlusion. Plasma NPY concentration significantly increased during aortic occlusion, but not $\mathrm{CPB}$, in both age groups. The older than age 1 year group had a significantly greater increase in plasma NPY level than the younger group: younger than 1 year, pre-CPB NPY $194.3 \pm 23.0 \mathrm{pg} / \mathrm{ml}$; pre-AO NPY $227.6 \pm 29.5 \mathrm{pg} / \mathrm{ml}$ and older than 1 year, pre-CPB NPY $72.7 \pm$ $11.8 \mathrm{pg} / \mathrm{ml}$; pre-AO NPY $78.9 \pm 12.3 \mathrm{pg} / \mathrm{ml} .{ }^{*} p<0.05$ versus younger than age 1 year.

lesions or the degree of hypothermia might have contributed to the differences in plasma NPY response during aortic occlusion in the two groups. There was no significant difference in pre-CPB plasma NPY concentrations between children with cyanotic and acyanotic lesions. The presence of cyanotic lesions also did not have any effect on the magnitude of change in plasma NPY concentrations during aortic occlusion (data not shown). Though younger patients were cooled to lower core temperatures during CPB than older children, the relative change in plasma NPY concentration was not correlated with the nadir of hypothermic temperature $(r=$ $+0.173,95 \% \mathrm{CI}-0.12,+0.47, p=0.25$ ) (Fig. 4).

\section{Discussion}

The main findings of this study were that resting plasma NPY concentrations measured before CPB declined with increased age and that change in NPY concentrations can be used in pediatric patients to assess the response of the sympathetic nervous system. Although levels of both plasma catecholamines and NPY have been documented to decline in an age-dependent fashion in healthy children, ${ }^{13,14}$ in children with congenital cardiac defects in the present study an age-dependent decline was only observed for pre-CPB plasma NPY levels, but not for plasma catecholamine levels. The heterogeneity of diagnoses among patients probably contributed to the large variability in levels of both plasma catecholamines and NPY. The higher plasma concentrations of catecholamines in the very young might be the result of immaturity in catecholamine metabolism or uptake, or both, leading to a greater amount of "spillover" into the plasma even though there may be reduced synthesis or release, 
whereas the higher plasma NPY levels in younger children may be a result of maturational differences in the amount or activity of plasma peptidases that metabolize NPY.

There is indirect evidence that the ontogeny of the human cardiovascular sympathetic nervous system, similar to that in other mammalian species, ${ }^{15-17}$ is not fully established until well into the postnatal period. ${ }^{18-21}$ Human neonates, however, can mount a sympathetic response, as evidenced by substantial increases in plasma norepinephrine and epinephrine levels during CPB in children anesthetized with morphine and halothane, ${ }^{3}$ as was the case with adults undergoing $\mathrm{CPB}$ who received halothane, morphine, and fentanyl. ${ }^{1}$ The stress response, however, is highly dependent on the depth of anesthesia. Interestingly, "deep" anesthesia with high doses of sufentanil, which have been found to consistently blunt the sympathetic response during bypass in the adult population, also abolished the increases in catecholamine levels in neonates. ${ }^{3}$ Our data show that high doses of fentanyl were also able to blunt the increases in plasma catecholamine levels during aortic occlusion, although significant increases in levels of plasma NPY were still evident in all age groups. This is consistent with the idea that even very young children can generate a sympathetic response, but the response was only detectable by changes in plasma NPY and not plasma catecholamines.

An elevation in plasma catecholamine and NPY concentrations has been consistently observed in patients with increased activation of the sympathetic nervous system. ${ }^{9}$ Increased plasma concentrations of catecholamines and NPY have been observed during intense sympathetic stimulation, such as aortic occlusion during $\mathrm{CPB} .{ }^{2}$ As in adult patients undergoing cardiac operation, plasma catecholamine levels did not change significantly during CPB in our pediatric population. In contrast to adults receiving high-dose fentanyl anesthesia who showed an increase in levels of both plasma norepinephrine and NPY after release of aortic occlusion, ${ }^{2}$ our patients only showed an increase in plasma NPY level. When patients were divided into two age groups, plasma NPY levels increased significantly more in the older compared with the younger children. This could not be attributed to the fact that the two groups of children were cooled to different hypothermic temperatures, because we were unable to demonstrate any relationship between the nadir of hypothermic temperature and changes in plasma

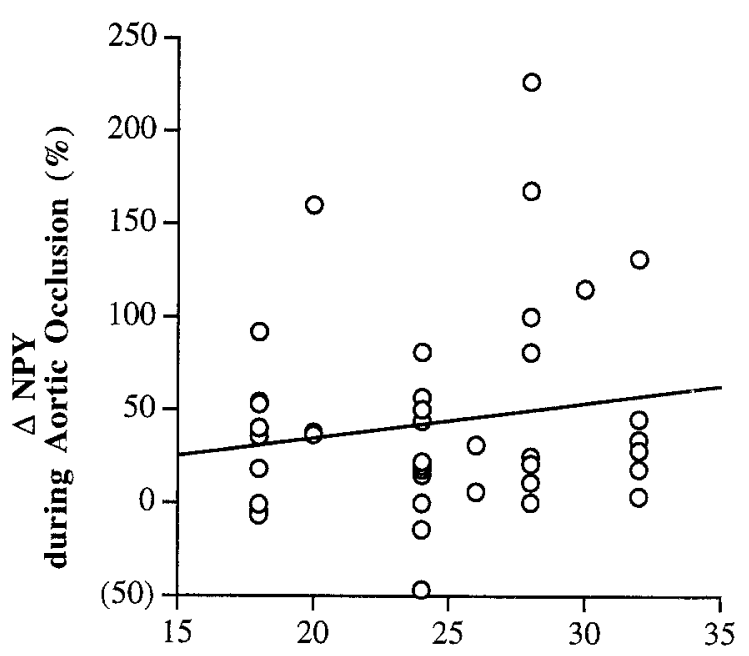

Nadir of Hypothermic Temperature $\left({ }^{\circ} \mathrm{C}\right)$

Fig. 4. Correlation between change $(\Delta)$ in plasma NPY concentration during aortic occlusion and the nadir of hypothermic temperatures $(r=+0.173,95 \% \mathrm{CI}-0.12$, $+0.47, p=0.25$ ).

NPY concentration during aortic occlusion. If the change in plasma NPY concentration during aortic occlusion can be thought of as a rough measure of NPY spillover from the heart, then there was more myocardial release of NPY in older children than in younger ones. It is possible that this was because of a greater sympathetic response in the more mature myocardium. Alternatively, the age-related differences in sympathetic response to aortic occlusion might be a result of the preexistent state of sympathetic nervous system activation. There was a significant age-dependent decrease in pre-CPB and pre-AO levels of plasma NPY. However, our regression analysis failed to demonstrate any interaction between age and pre-CPB or pre-AO plasma NPY concentration with respect to the relative change in plasma NPY concentration during aortic occlusion. Nevertheless, the capacity of the sympathetic nervous system to further respond might be limited in the younger children either as result of the immaturity of the system or its preexisting sympathetic activation. That the pattern of age-dependent decline in plasma NPY concentration was preserved in pediatric patients undergoing cardiac operation, despite the large variability among patients, and that changes in plasma NPY concentration could be detected in response to aortic occlusion suggest that perhaps plasma NPY may be a more useful marker 
of sympathetic nervous system activation in the pediatric patient population.

In conclusion, our data demonstrated that patients with congenital cardiac defects have elevated concentrations of pre-CPB plasma catecholamines at all ages, whereas the pre-CPB plasma NPY concentration in these patients declined in an agedependent manner. In response to CPB or aortic occlusion there was no change in plasma catecholamine levels, but an increase in plasma NPY level was observed in response to aortic occlusion. The NPY response to aortic occlusion was greater in the older than the younger than 1-year-old age group, which may be because the age-dependent pattern of pre-CPB plasma NPY level permitted a greater margin from which to detect an increase in plasma NPY level after intense stimulation with aortic occlusion. Thus our results suggest that (1) there may be an age-dependent difference in sympathetic response and (2) plasma NPY may be a useful marker for the assessment of the response of the sympathetic nervous system in the pediatric patient undergoing cardiac operation.

We would like to thank Dr. Amy Jonassen, Dr. Jonathan Lesser, and all of the residents and perfusionists who participated in the collection of samples for the study.

\section{REFERENCES}

1. Reves JG, Karp RB, Buttner EE, et al. Neuronal and adrenomedullary catecholamine release in response to cardiopulmonary bypass in man. Circulation 1982;66:49-55.

2. Franco-Cereceda A, Owall A, Settergren G, Sollevi A, Lundberg JM. Release of neuropeptide $Y$ and noradrenaline from the human heart after aortic occlusion during coronary artery surgery. Cardiovasc Res 1990;24:242-6.

3. Anand KJS, Hickey PR. Halothane-morphine compared with high-dose sufentanil for anesthesia and postoperative analgesia in neonatal cardiac surgery. N Engl J Med 1992;326:1-9.

4. Anand AJS, Hansen DD, Hickey PR. Hormonal-metabolic stress responses in neonates undergoing cardiac surgery. Anesthesiology 1991;73:661-70.

5. Weiner N, Taylor P. Neurohumoral transmission: the autonomic and somatic nervous systems. In: Gilman AG, Goodman LS, Rau TW, et al., editors. Pharmacological basis of therapeutics. New York: Macmillan, 1985:66-99.
6. Pappano A. Ontogenetic development of autonomic neuroeffector transmissions and transmitter reactivity in embryonic and fetal hearts. Pharmacol Rev 1977;29:3-33.

7. Potter EK. Neuropeptide $Y$ as an autonomic neurotransmitter. Pharmacol Ther 1988;37:251-73.

8. Lundberg JM, Hökfelt T. Coexistence of peptides and classical neurotransmitters. Trends Neurosci 1983;6:325-33.

9. Pernow J, Lundberg J, Kaijser L, et al. Plasma neuropeptide Y-like immunoreactivity and catecholamines during various degrees of sympathetic activation in man. Clin Physiol 1986; 6:561-78.

10. Rudehill A, Franco-Cereceda A, Hemsén A, Stensdotter M, Pemow J, Lundberg JM. Cigarette smoke-induced elevation of plasma neuropeptide Y levels in man. Clin Physiol 1989; 9:243-8.

11. Pernow J, Lundberg JM, Kaijser L. Vasoconstrictor effects in vivo and plasma disappearance rate of neuropeptide $\mathrm{Y}$ in man. Life Sci 1987:40:47-54.

12. Zar JH. Biostatistical analysis. Englewood Cliffs, New Jersey: Prentice-Hall, 1974:151-62,230-2,240-1,273-4.

13. Candito M, Albertini M, Politano S, Deville A, Mariani R, Chambon P. Catecholamine levels in children. J Chromatogr 1993;617:304-7.

14. Kogenr P, Bjork O, Theodorsson E. Plasma neuropeptide $Y$ in healthy children: influence of age, anesthesia and the establishment of an age-adjusted reference interval. Acta Paediatr 1994;83:423-7.

15. Friedman WF, Pool PE, Jacobwitz D, Seagren SC, Braunwald E. Sympathetic innervation of the developing rabbit heart. Circ Res 1968;23:25-32.

16. Ursell PC, Ren CL, Danilo P Jr. Anatomic distribution of autonomic neural tissue in the developing dog heart: I-sympathetic innervation. Anat Rec 1990;226:71-80.

17. Nyquist-Battie C, Cochran PK, Sands SA, Chronwall BM. Development of neuropeptide $\mathrm{Y}$ and tyrosine hydroxylase immunoreactive innervation in postnatal rat heart. Peptides $1994 ; 15: 1461-9$

18. Dohi S, Naito H, Takahashi T. Age-related changes in blood pressure and duration of motor block in spinal anesthesia. Anesthesiology 1979;50:319-23.

19. Clairambault J, Curzi-Dascalova L, Kaufmann F, Medigue C, Leffier C. Heart rate variability in normal sleeping full-term and preterm neonates. Early Hum Dev 1992;28:169-83.

20. Yeragani VK, Pohl R, Berger R, Balon R, Srinivasan K. Relationship between age and heart rate variability in supine and standing postures: a study of spectral analysis of heart rate. Pediatr Cardiol 1994;15:14-20.

21. Chow LT, Chow SS, Anderson RH, Gosling JA. Innervation of the human cardiac conduction system at birth. Br Heart $\mathrm{J}$ 1993;69:430-5. 